International Review of Research in Open and Distributed Learning Volume 18, Number 1

February - 2017

\title{
Analysis of Social Media Influencers and Trends on Online and Mobile Learning
}

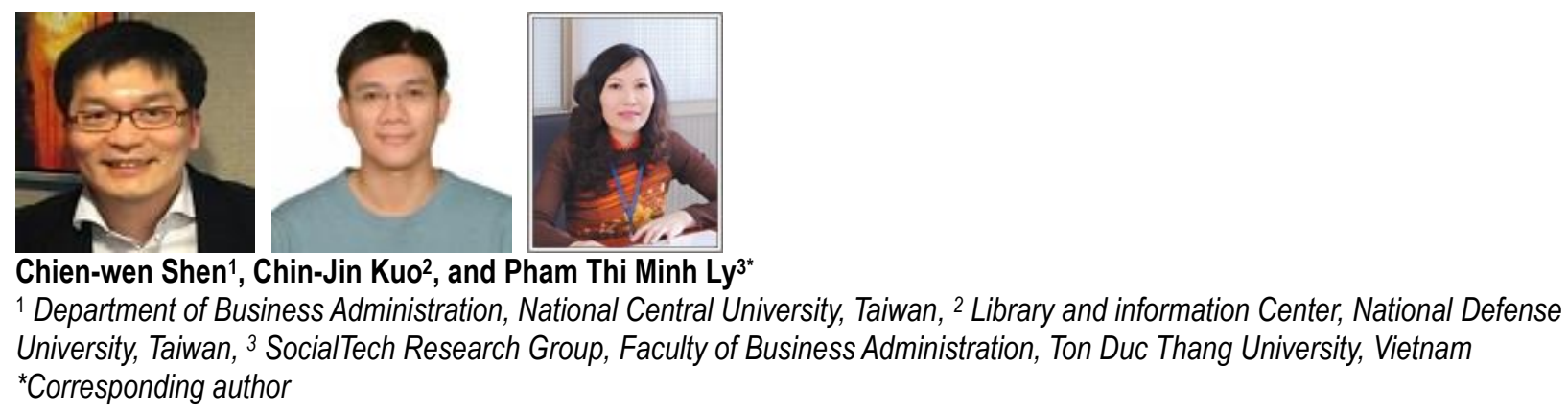

\section{Abstract}

Although educational practitioners have adopted social media to their online or mobile communities, little attention has been paid to investigate the social media messages related to online or mobile learning. The purpose of this research is to identify social media influencers and trends by mining Twitter posts related to online learning and mobile learning. We identified the influencers on Twitter by three different measures: the number of tweets posted by each user, the number of mentions by other users for each user, and the number of retweets for each user. We also analyzed the trends of online learning and mobile learning by the following perspectives: the descriptive statistics of the related tweets, the monthly and hourly line charts of the related tweets, the descriptive statistics of the related retweets, the volume trends of the most retweeted tweets, and the top 10 hashtags of the related tweets. The results of this study can provide educational practitioners different ways of understanding and explaining the public opinions toward online learning and mobile learning.

Keywords: online learning, mobile learning, social media, social media influencers, social media trends, Twitter 


\section{Introduction}

With the rapid growth of the Internet and the World Wide Web, online learning is becoming an increasingly important mode of education, which allows students to participate regardless of geographic location, independent of time and place (Harasim, 1995). There are numerous names for online learning activities such as e-learning, web-based learning/training, Internet-based training, distributed learning, digital collaboration, and distance learning (Khan, 2005). In online learning environments, social negotiation and collaboration are supported through the use of document sharing tools and groupware as well as asynchronous and synchronous communication technology (Dabbagh, 2004). Recent development of communication technology, especially mobile communication technology, facilitate students' engagement in online education and lead to the emerging of mobile learning. Mobile learning provides an alternative way to learn online with advantages of better access, smaller device, flexibility, and ubiquity (Lam, Yau, \& Cheung, 2010). It not only connects people in information-driven societies effectively, but also provides the opportunity for a spontaneous, personal, informal, and situated learning (Shih, 2007).

Over the past decade, online social networking sites such as Facebook and Twitter are one of the communications technologies that have been widely-adopted by students (Roblyer, McDaniel, Webb, Herman, \& Witty, 2010). Educational practitioners have also adopted social networking tools to online learning communities for their course design and delivery ( $\mathrm{Lu}, \mathrm{Yang}, \& \mathrm{Yu}, 2013$ ). By connecting mobile learning to social media sites, learners can get the necessary contextual information from the other users (Frohberg, Göth, \& Schwabe, 2009). Social networking technologies, and media can foster interaction and communication between students and instructors, because students may have limited face-to-face time to build a support network with their peers in online or mobile learning environments. The "bridge" on social media plays an important part in student motivation, retention, and learning in distributed learning environments (Baird \& Fisher, 2005). Although social media and online/mobile learning are shaping educational technology, little attention has been paid to investigate the social media messages related to online or mobile learning. By mining these messages, we may find insights in the public perception about online and mobile learning and response to enhance participants' elearning experience. Hence, the purpose of this research is to identify social media influencers and trends by analyzing Twitter posts (tweets), because Twitter is among the top three social networking sites in the world and its data is public and searchable. To identify the Twitter influencers on the topics of online learning and mobile learning, we analyzed the following measures: the number of tweets posted by each user, the number of mentions by other users for each user, and the number of retweets for each user. A mention on Twitter is used to acknowledge someone's association to the content of the tweet or attract someone's attention (Hong, Convertino, \& Chi, 2011). A retweet is a "message from one user that is forwarded by a second user to the second user's followers" (Naaman, Becker, \& Gravano, 2011, p. 903). The measure of mention and the measure of retweet were used in this study to identify 
the influencers on the topics of online learning and mobile learning, because the users with the greatest numbers of mentions and retweets indicate that their posts are followed by a massive number of interested and engaged fans. Knowing the social media influencers is important to educational practitioners, because it's important to build connections with the influencers in order to proactively leverage social media to promote online learning or mobile learning courses (Shen \& Kuo, 2015). In addition, we analyzed the trends of online learning and mobile learning by the following perspectives: the descriptive statistics of the related tweets, the monthly and hourly line charts of the related tweets, the descriptive statistics of the related retweets, the volume trends of the most retweeted tweets, and the top 10 hashtags of the related tweets. These perspectives can provide educational practitioners different ways of understanding and explaining the public opinions toward online learning and mobile learning.

The remainder of this paper is organized as follows. The next section reviews the literature addressing the topics of online learning and mobile learning with the use of social media or social networking technologies. The approach of data collection and methods of data analysis is presented in Section 3. In Section 4, the findings of analysis on social media influencers and trends are identified and discussed. The paper ends with a conclusion, implications for educational practitioners, and an outlook for further research.

\section{Online and Mobile Learning with Social Media}

Social media generally encompasses social networking sites, media sharing sites, creation and publishing tools, aggregation and republishing through RSS feed, and remixing content and republishing tools (Greenhow, 2011). For the young generation, social media exchanges are a primary means of communication, information seeking, and social engagement as well as a key component of their community-building and identity (Davis III, Deil-Amen, Rios-Aguilar, \& González Canché, 2015). Thus, social media are increasingly visible in higher education settings as instructors look to the related technology to promote active learning for students as well as mediate and enhance their instruction (Tess, 2013). For the online learning environment, many instructors have also adopted popular online social media in response to the increasing demand for synchronous virtual learning tools (Lu et al., 2013). Several studies have been conducted to evaluate the feasibility of using social media for online learning. For example, Dunlap and Lowenthal (2009) described the use of Twitter to encourage freeflowing, just-in-time interactions in online courses. Besides the benefits of enhancing social presence during online learning, they indicated that Twitter can also have instructional benefits on addressing student issues in a timely manner, writing concisely, writing for an audience, connecting with a professional community of practice, supporting informal learning, and maintaining on-going relationships. Sarsar and Harmon (2011) examined the attitudes of undergraduate students toward Facebook as a potential learning environment. Results indicate that students did not rely on social media for providing quality education. They preferred Facebook as a part of online learning 
environment and concerned about the safety and privacy of online learning environment with social media. Ostashewski and Reid (2012) proposed a social networking site situated massive open online course. This course was delivered within a social networking site group and its learning activities utilized social media tools for content delivery and student engagement. Brownson (2014) stated that embedding social media into distance-learning classes can increase the level of interaction in an online course, because social learning and collaboration can support greater levels of interaction and higher retention rates. Rothkrantz (2014) presented a didactical model for open and online learning using social media. This model focused on the interaction in the learning groups of social media, which provides students an identity in a group and a feeling of presence. Social control and interactions with peers in the proposed model can also increase motivation of students and self-awareness and stimulates study-activities. Hence, many research have supported the importance of social media on teaching and learning in higher education (Sobaih, Moustafa, Ghandforoush, \& Khan, 2016).

Meanwhile, the availability of mobile technology has further fueled the importance of social media in mobile learning. Much research has also been conducted to evaluate the integration with social media and mobile learning. For example, Lewis, Pea, and Rosen (2010) described an informal learning social media application that embraced the concepts of mobile media blitz with the intentional emphasis on the syllable "mob." They sought to build an application that would foster the development of generative learning communities. Gikas and Grant (2013) explored teaching and learning when mobile computing devices were implemented in higher education. Their findings indicated that mobile devices and the use of social media can create opportunities for interaction, provide opportunities for collaboration, as well as allow students to engage in communication and content creation. Through the use of social media, students within their coursework reported that they communicated more about course content. Cochrane et al. (2014) proposed a framework for supporting and implementing mobile social media for pedagogical change within higher education. The framework mapped the approaches of authentic learning, educational technology adoption framework, and creativity onto the Pedagogy-AndragogyHeutagogy continuum as applied to the context of mobile learning. Norman, Nordin, Din, Ally, and Dogan (2015) investigated the roles of social participation in mobile social media learning. Their analysis identified four roles, which include lurkers, gradually mastering members/passive members, recognized members, and coaches. Liu and Huang (2015) proposed a system called M-Learning 2.o by integrating social media into conventional mobile learning. This aim of this system is to promote collaborative sharing of life experiences in nature and discussion of different perspectives. A pilot case study discussed how students collaboratively taking photos via the use of a mobile application. 


\section{Data Collection and Methodology}

We started our investigation by collecting Twitter messages containing the words "Mobile Learning" or "Online Learning." We used the search API provided by Twitter to write codes for data collection and analysis. For example, the following Python code is used to pull out retweet origins of a tweet:

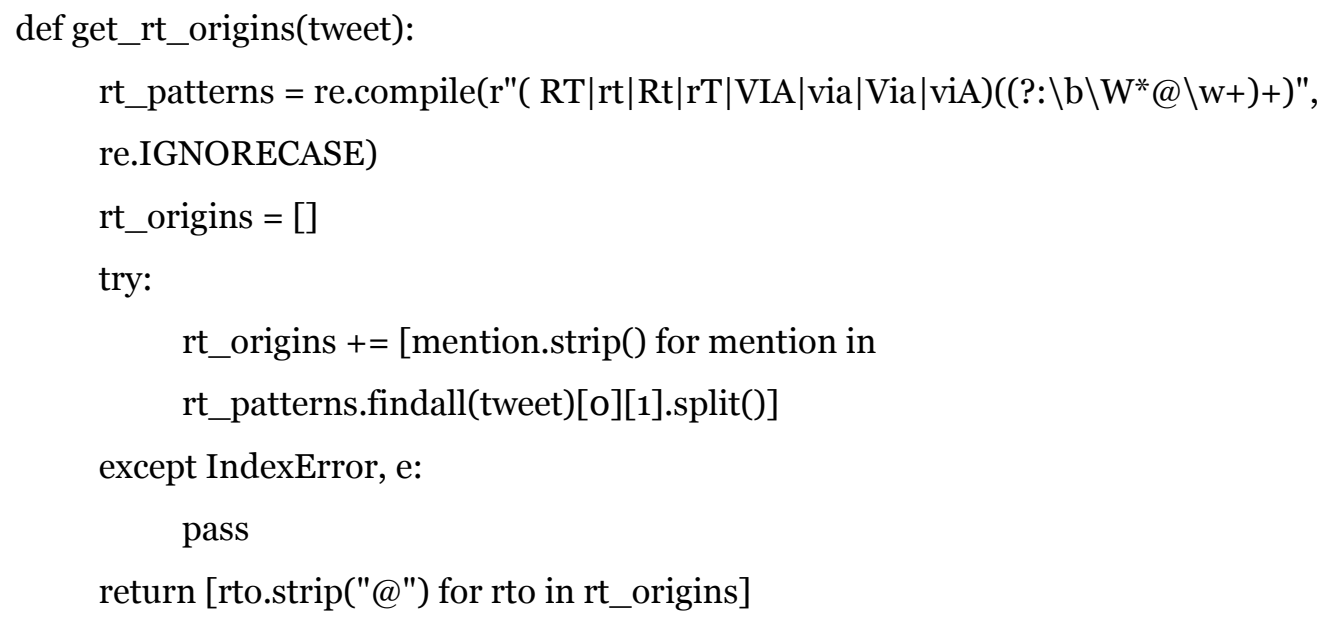

The data collection period started on July 1st, 2014 and ended on June 30, 2015. The total number of the tweets about mobile learning and online learning were 113,372 and 177,099, respectively. Based on the collected data, we first analyzed the trends of mobile learning and online learning by describing the descriptive statistics (daily maximum, daily minimum, standard deviation, daily mean, weekly mean, monthly mean, weekday means, and weekend means) of the related tweets. We also outlined the trends by plotting their monthly and hourly line charts. Moreover, the trends of retweets were analyzed by the statistics of yearly total, number of retweeting users, and average number of tweets reposted by the users. The most retweeted tweets of mobile learning and online learning were identified also and their volume trends over time were depicted. Additionally, because hashtag is a Twitter convention allowing users to create or follow a thread of discussion by prefixing a tweet with a hashtag (Fortin, Uncles, Burton, \& Soboleva, 2011), we examined the trends by identifying the top 10 hashtags related to mobile learning and online learning.

Subsequently, we investigated the influencers of information dissemination about mobile learning and online learning on Twitter. In this study, the user accounts with the greatest number of tweets on mobile learning and online learning were identified as influencers. In addition, a mention in Twitter consists of inclusion of username in the body of tweets with maximum 140 characters (Shin, Singh, Cho, \& Everett, 2015). Hence, the user accounts with the highest number of mentions by other users are also identified as the influencers on Twitter in this study. Moreover, the retweet mechanism on Twitter enables people to share messages with their followers and provides people a channel to endorse their perspectives regarding specific topic (Borondo, Morales, Losada, \& Benito, 2012). A retweet commonly use the "RT @username" text as prefix to credit the original poster (Naaman et al., 2011). Thus the users with the greatest number of retweets are also identified as the influencers on Twitter. These influencers 
play important roles on sharing the information about mobile learning and online learning to their massive number of followers.

\section{Findings}

\section{Analysis of Social Media Trends}

In order to illustrate the general trends of mobile learning and online learning on Twitter, some descriptive statistics are presented in Table 1. For the statistics of mobile learning, their daily maximum, daily minimum, standard deviation, and daily mean were $841,91,106.83$, and 310.61 respectively. The date with the highest number of tweets was on February 23, 2015, because there was an important tweet, "Mobile Power for Girl Power: UNESCO \&amp; @UN_Women are gearing up for Mobile Learning Week \#MLW2015 http://t.co/uPvatKNj5T," posted by many users on that date. This Twitter message shared the news about the theme of Mobile Learning Week 2015 hosted by UNESCO. Meanwhile, the daily maximum, daily minimum, standard deviation, and daily mean of the tweets related to online learning were 3,984, 127, 303.15, and 485.20 respectively. April 9, 2015 is the date with the highest number of tweets related to online learning because many users talked about the tweet "LinkedIn just dropped $\$ 1.5$ billion to buy online learning company Lynda http://t.co/35ZNoSbYNU." Lynda is a popular online resource for learning software, business, creative, and technology skills. Moreover, the statistics in Table 1 indicate that the discussion about online learning was more popular than mobile learning because the daily mean of the mobile learning tweets was approximately $60 \%$ of the online learning tweets. We also observed that the discussions about mobile learning or online learning on Twitter were about 50\% higher on weekdays than at the weekends.

Table 1

Descriptive Statistics of the Tweets Related to Mobile and Online Learning

\begin{tabular}{lrr}
\hline Statistics & Mobile learning & Online learning \\
& 841 & 3,984 \\
Daily maximum & 91 & 127 \\
Daily minimum & 106.83 & 303.15 \\
Standard deviation & 310.61 & 485.20 \\
Daily mean & & $3,394.63$ \\
Weekly mean & $2,173.56$ &
\end{tabular}


Monthly mean

Weekday mean

Weekend mean
$9,447.67$

341.83

232.26
$14,758.25$

552.02

$317 \cdot 52$

The trends of mobile learning and online learning can be also learned by the line charts of their monthly and hourly tweets, which are shown in Figure 1. On the top of Figure 1 is the line chart of the monthly tweets for mobile learning (dash line) and online learning (solid line). It indicates that the talks about online learning on Twitter were more prevalent than mobile learning throughout the year. While the biggest monthly differences occurred in April, the smallest monthly differences occurred in February. The line chart of the hourly tweets shown at bottom of Figure 1 also indicates that the topics about online learning are more popular than mobile learning throughout the day. Twitter users were more likely to post their tweets during the afternoon period.
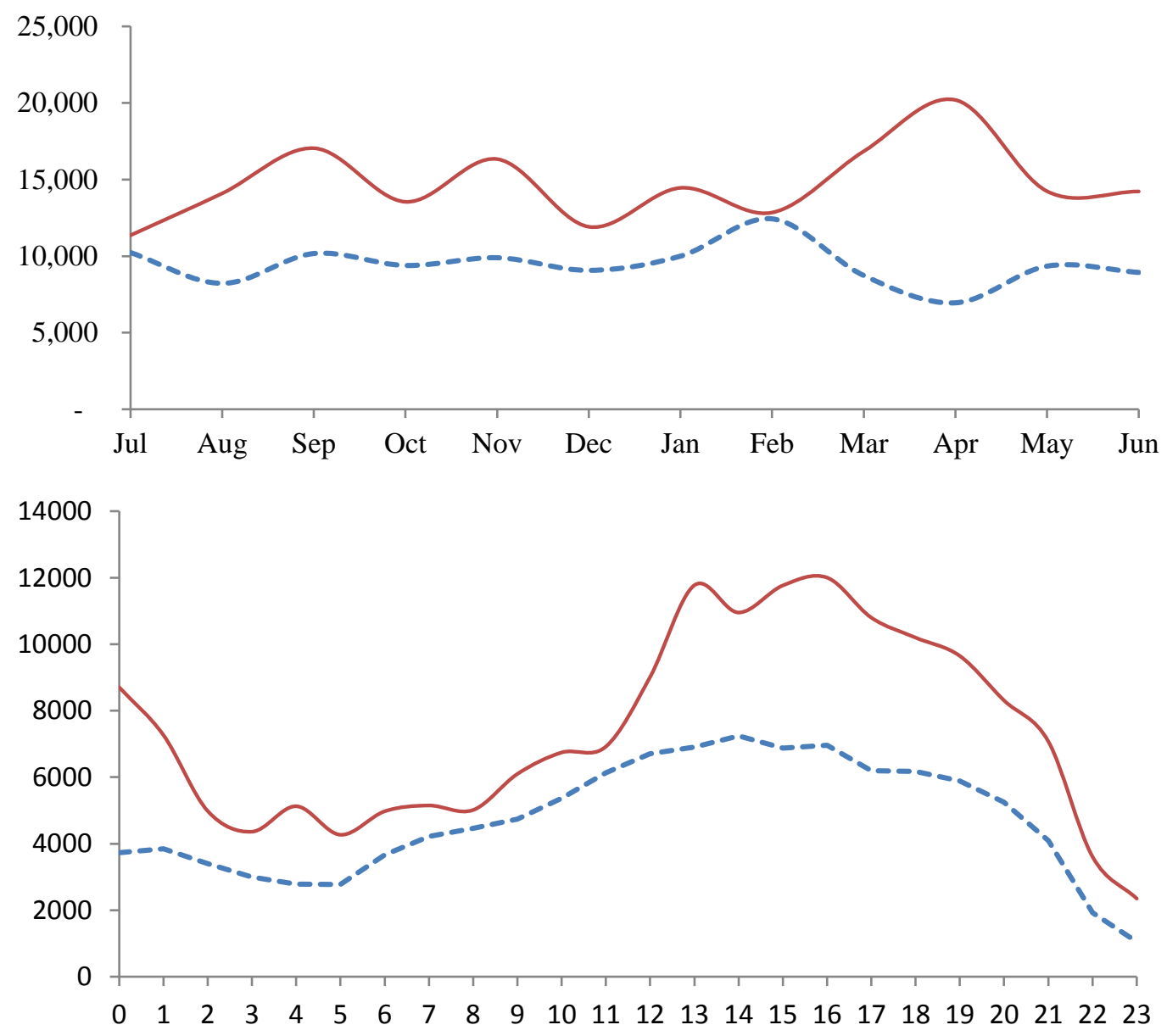

----- Mobile Learning — Online Learning

Figure 1. Monthly and hourly line charts of the tweets. 
To understand the trends of retweets, Table 2 summarizes the descriptive statistics of the retweets related to mobile learning and online learning. The yearly total of mobile learning retweets and online learning retweets were 42,765 and 64,765 respectively. Although the posts about online learnings were retweeted more often than mobile learning, the average number of online learning retweets was 4.87 , which is fewer than the average number of mobile learning retweets. It implies that the Twitter users who concerned about mobile learning were more willing to share related messages to others than those who concerned about online learning.

Table 2

Descriptive Statistics of the Retweets

\begin{tabular}{lcc}
\hline \multicolumn{1}{c}{ Statistics } & Mobile learning & Online learning \\
\hline Yearly total & 42,765 & 64,765 \\
(Percentage \%) & $(37.72 \%)$ & $(36.57 \%)$ \\
Number of users & 8,282 & 13,274 \\
(Percentage \%) & $(22.03 \%)$ & $(15.48 \%)$ \\
Average Retweets/User & 5.10 & 4.87 \\
\hline
\end{tabular}

Among the retweets related to mobile learning, "Help make it happen for i-Skool: Revolution In Mobile Learning on @indiegogo http://t.co/GNmurZbccm \#crowdfunding” was the most retweeted message. It was originally posted on April 6, 2015 and retweeted 105 times during our data collection period. This message is about a crowdfunding project of $\mathrm{i}$-Skool, which is a technology aimed at improving learning abilities by creating thinking tasks correlating to physical activities. Meanwhile, "\#StartUps Looop, An Online Learning Platform For Employees, Raises \$2M To Enter... http://t.co/gaFz7kgLqo \#NewsFeed http://t.co/M5oFTNjoVj” was the most retweeted message related to online learning. It was originally posted on September 11, 2014 and retweeted 1,684 times in a year. This message shared the news about an Australia startup, Looop, received a \$2 million seed round from an education investor. In addition, the number of times that these two most retweeted messages were reposted by other users over a 10day period were illustrated in Figure 2. The figure shows that almost all retweets made within 1 hour. Hence, the timing of tweet posting is important to the effectiveness of information dissemination on Twitter. 


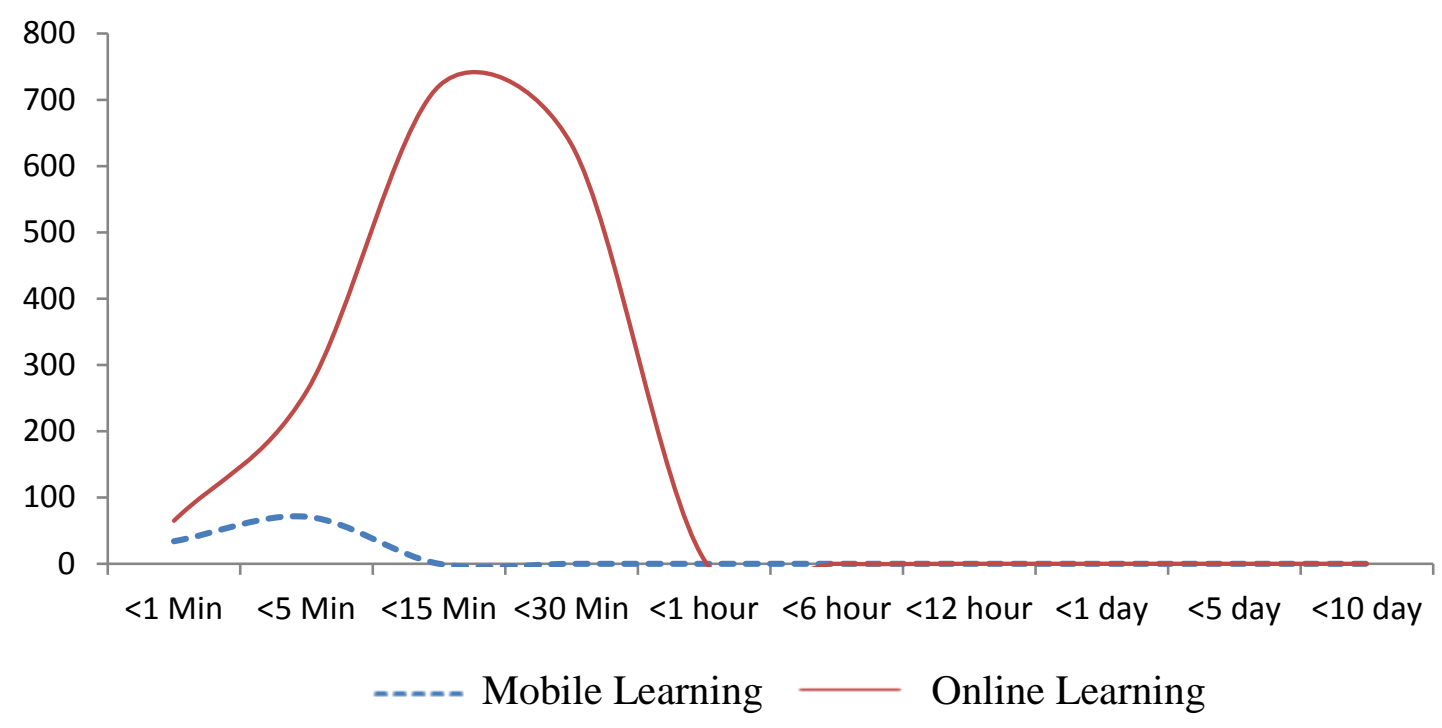

Figure 2. The volume trends of the most retweeted posts.

Additionally, we can probe the trends of mobile learning and online learning by identifying the top 10 hashtags mentioned in the related tweets (see Table 3). For the tweets of mobile learning, we can observe that \#edtech, \#mlearning, \#mobile, \#elearning, \#learning, \#edchat, \#mobilelearning, \#MLW2015, \#education, and \#BYOD were the top 10 hashtags. Among them, \#edtech, \#edchat, \#MLW2015, \# education, and \#BYOD are the hashtags that are not the synonyms/clippings of mobile learning. Edtech is the most popular hashtag mentioned in the tweets related to mobile learning. Tweets with \#Edtech generally covers the messages for educational technology fans on Twitter. Edchat is another similar hashtag where people have talks and chats about educational technology. MLW2015 is an online campaign launched for UNESCO Mobile Learning Week 2015 co-hosted by UN Women. Hashtag BYOD is filled with tweets describing ways in which students can use their own personal technology. Meanwhile, for the tweets of online learning, \#edtech, \#highered, \#Podcast, \# edchat, and \#Udemy were the top hashtags that are not the synonyms/clippings of online learning. Tweets with hashtag "highered" usually cover the news about online learning initiatives on higher education. Hashtag Podcast provides the links of online learning information in audio format. \#Udemy is a hashtag where people talks about the courses offered by Udemy, which is one of the world's most popular destinations for online learning. 
Table 3

Top 10 Hashtags Related to Mobile Learning and Online Learning

\begin{tabular}{clrrcrr}
\hline \multirow{2}{*}{ Rank } & \multicolumn{3}{c}{ Mobile learning } & \multicolumn{3}{c}{ Online learning } \\
\cline { 2 - 7 } & Hashtag & Count & Percentage & Hashtag & Count & Percentage \\
\hline 1 & \#edtech & 8,215 & $9.34 \%$ & \#learning & 8,947 & $5.86 \%$ \\
2 & \#mlearning & 7,877 & $8.96 \%$ & \#online & 8,590 & $5.63 \%$ \\
3 & \#mobile & 5,252 & $5.97 \%$ & \#elearning & 8,071 & $5.29 \%$ \\
4 & \#elearning & 4,697 & $5.34 \%$ & \#edtech & 7,773 & $5.09 \%$ \\
5 & \#learning & 3,113 & $3.54 \%$ & \#education & 4,246 & $2.78 \%$ \\
6 & \#edchat & 2,505 & $2.85 \%$ & \#onlinelearning & 3,875 & $2.54 \%$ \\
7 & \#mobilelearning & 2,321 & $2.64 \%$ & \#highered & 2,723 & $1.78 \%$ \\
8 & \#MLW2015 & 1,844 & $2.10 \%$ & \#Podcast & 2,432 & $1.59 \%$ \\
9 & \#education & 1,469 & $1.67 \%$ & \#edchat & 2,377 & $1.56 \%$ \\
10 & \#BYOD & 941 & $1.07 \%$ & \#Udemy & 2,114 & $1.38 \%$ \\
\hline & Total & 38,234 & $43.47 \%$ & & 51,148 & $33.50 \%$
\end{tabular}

\section{Analysis of Social Media Influencers}

To investigate the influencers of information dissemination regarding mobile learning and online learning on Twitter, we identified the top users who posted the greatest number of related tweets and summarized in Table 3. Regarding the influencers of mobile learning, most of the top 10 users were personal accounts, which include users @mikejohnson_21, @MarkEDeschaine, @guzmanadrian, @fernandonaranjo, @Aprendeme, @juandoming, and @asgitsolutions. Top user @mikejohnson_21, a high school teacher from South Winneshiek Community School District, posted the greatest number of tweets related to mobile learning (749 tweets). The total tweets of the top 10 users account for $4.73 \%$ of the mobile learning tweets in a year. On the other hand, among the influencers of online learning, only the accounts of @OLPodcast and @EllenKramer were the personal accounts. Top user @OLPodcast, a strategic marketing professional who provides resource of online learning podcast, posted the greatest number of tweets related to online learning (1,920 tweets). The total tweets of the top 10 users account for $4.44 \%$ of the mobile learning tweets in a year. Hence, the influencers listed in Table 3 play important roles in posting tweets related to of mobile learning or online learning. 
Table 4

Top 10 Users by the Number of Tweets

\begin{tabular}{clrrlrr}
\hline \multirow{2}{*}{ Rank } & \multicolumn{3}{c}{ Mobile learning } & \multicolumn{3}{c}{ Online learning } \\
\cline { 2 - 7 } & \multicolumn{1}{c}{ User ID } & Count & Percentage & User ID & Count & Percentage \\
\hline 1 & @mikejohnson_21 & 749 & $0.66 \%$ & @OLPodcast & 1,920 & $1.08 \%$ \\
2 & @UpsideLearning & 626 & $0.55 \%$ & @EllenKramer & 1,032 & $0.58 \%$ \\
3 & @MarkEDeschaine & 585 & $0.52 \%$ & @HomeopathyWTF & 1,009 & $0.57 \%$ \\
4 & @guzmanadrian & 583 & $0.51 \%$ & @CouponIgnite & 827 & $0.47 \%$ \\
5 & @WebTeachersUK & 540 & $0.48 \%$ & @OnlineStudyNews & 578 & $0.33 \%$ \\
6 & @fernandonaranjo & 524 & $0.46 \%$ & @ISTE_OLNetwork & 531 & $0.30 \%$ \\
7 & @elemenous & 464 & $0.41 \%$ & @BINUSOnline & 508 & $0.29 \%$ \\
8 & @Aprendeme & 439 & $0.39 \%$ & @_OnlineDegree & 505 & $0.29 \%$ \\
9 & @juandoming & 430 & $0.38 \%$ & @schoolkeep & 502 & $0.28 \%$ \\
10 & @asgitsolutions & 428 & $0.38 \%$ & @AlumniNETNews & 443 & $0.25 \%$ \\
\hline & Total & 5,368 & $4.73 \%$ & & 7,855 & $4.44 \%$
\end{tabular}

From the perspective of mention mechanism on Twitter, users can contain other users' account names in the body of tweets to show their relevance to the topics of tweets. Hence, the number of mentions can be used to measure the influencers on Twitter. Table 5 shows a summary of the top 10 users with the greatest number of mentions. Regarding the tweets of mobile learning, @scoopit and @medkh9 were among the most frequently mentioned usernames in the related tweets. User @scoopit is a company named Scoop.it, which provides tools and platforms to help users to discover, curate, and publish content to get visibility online. User @ medkh9 is a company providing resources of educational web tools and mobile apps for teachers and educators. These top two users were vital to the information dissemination of mobile learning on Twitter, because they accounted for $24.88 \%$ of the total user mentions in a year. On the other hand, among the tweets related to online learning, the top three users, @BestWorstOnline, @scoopit, and @RealTonyRocha, with the highest number of mentions only accounted for $5.09 \%$ of the total user mentions. User @BestWorstOnline is an international higher education and training consultancy. User @ RealTonyRocha is a radio and TV director with a PhD in communication. Users @scoopit and @elearningindustry were the only two most frequently mentioned usernames in both the tweets of mobile learning and online learning. Other notable accounts related to mobile learning include @UNESCO and @UN_Women. Both UN organizations promote the importance of mobile learning because it is affordable and has the advantage to connect less privileged people to information. Meanwhile, the notable accounts related to the tweets of online learning include @TheEconomist, @Harvard, and @BillGates. Our findings indicate that online learning gains wider acceptance in media, higher education, and business magnate. 
Table 5

Top 10 Users by the Number of Mentions

\begin{tabular}{|c|c|c|c|c|c|c|}
\hline \multirow{2}{*}{ Rank } & \multicolumn{3}{|c|}{ Mobile learning } & \multicolumn{3}{|c|}{ Online learning } \\
\hline & User ID & Count & Percentage & User ID & Count & Percentage \\
\hline 1 & $@$ scoopit & 13,718 & $13.78 \%$ & @BestWorstOnline & 2547 & $1.92 \%$ \\
\hline 2 & $@$ medkh9 & 11,050 & $11.10 \%$ & @scoopit & 2523 & $1.90 \%$ \\
\hline 3 & @UNESCO & 1,441 & $1.45 \%$ & @RealTonyRocha & 1683 & $1.27 \%$ \\
\hline 4 & $@$ joevans & 1,187 & $1.19 \%$ & @TheEconomist & 1164 & $0.88 \%$ \\
\hline 5 & @UN_Women & 1,051 & $1.06 \%$ & @EllenKramer & 1152 & $0.87 \%$ \\
\hline 6 & @elearnindustry & 1,023 & $1.03 \%$ & @Harvard & 1094 & $0.82 \%$ \\
\hline 7 & @UpsideLearning & 748 & $0.75 \%$ & @elearnindustry & 961 & $0.72 \%$ \\
\hline 8 & $@ \operatorname{CoSN}$ & 730 & $0.73 \%$ & @BetaList & 911 & $0.69 \%$ \\
\hline 9 & $@$ MindShiftKQED & 724 & $0.73 \%$ & $@$ sciam & 862 & $0.65 \%$ \\
\hline 10 & @commlabindia & 682 & $0.68 \%$ & @BillGates & 825 & $0.62 \%$ \\
\hline & Total & 32,354 & $32.50 \%$ & & 13,722 & $10.33 \%$ \\
\hline
\end{tabular}

Finally, we identified the influencers on Twitter by the number of retweets. The top 10 users who had the greatest number of tweets reposted by other users are listed in Table 6. Users @ medkh9, $@$ @elearnindustry, and @MindShiftKQED were the top three users with the highest number of retweets on mobile learning and accounted for around 10\% of the total number of retweets. User @medkh9 was a significant influencer because the messages of @ medkh9 were reposted 3,178 times by other users, which is approximately six times more than the second place influencer. Users @medkh9 and @elearnindustry were also among the top 10 users with the greatest number of mentions on the tweets of mobile learning. Regarding the retweets of online learning, users @ BestWorstOnline, $@$ BestWorstOnline, and @TheEconomist were the top three users with the highest number of retweets on online learning and accounted for $6.41 \%$ of the total number of retweets. Users @ BestWorstOnline, @TheEconomist, @harvard, @sciam, @BillGates, @BetaList, and @elearnindustry were also among the top 10 users with the greatest number of mentions on the tweets of online learning. Thus, the influencers' messages on online learning were more likely to be mentioned and retweeted by the other users on Twitter. 
Table 6

Top 10 Users by the Number of Retweets

\begin{tabular}{clrrlrr}
\hline \multirow{2}{*}{ Rank } & \multicolumn{3}{c}{ Mobile learning } & \multicolumn{3}{c}{ Online learning } \\
\cline { 2 - 7 } & \multicolumn{1}{c}{ User ID } & Count & Percentage & User ID & Count & Percentage \\
\hline 1 & @medkh9 & 3178 & $7.51 \%$ & @RealTonyRocha & 1683 & $2.60 \%$ \\
2 & @elearnindustry & 531 & $1.26 \%$ & @BestWorstOnline & 1429 & $2.21 \%$ \\
3 & @MindShiftKQED & 518 & $1.22 \%$ & @TheEconomist & 1037 & $1.60 \%$ \\
4 & @joevans & 502 & $1.19 \%$ & @harvard & 754 & $1.16 \%$ \\
5 & @UN_Women & 405 & $0.96 \%$ & @sciam & 744 & $1.15 \%$ \\
6 & @UNESCO & 373 & $0.88 \%$ & @BillGates & 724 & $1.12 \%$ \\
7 & @UpsideLearning & 307 & $0.73 \%$ & @BetaList & 608 & $0.94 \%$ \\
8 & @edutopia & 301 & $0.71 \%$ & @TheNextWeb & 591 & $0.91 \%$ \\
9 & @educaintef & 288 & $0.68 \%$ & @elearnindustry & 529 & $0.82 \%$ \\
10 & @mobteacher & 272 & $0.64 \%$ & @wef & 513 & $0.79 \%$ \\
\hline & Total & 6,675 & $15.78 \%$ & & 8,612 & $13.30 \%$
\end{tabular}

\section{Conclusion}

Much of the current literature on online and mobile learning with social media focuses on the benefits of social media integration and the case studies of related applications. This research provides a different perspective from the analysis of social media trends and influencers on the topics of online learning and mobile learning. Different approaches are proposed in this study to identify social media trends and influencers on Twitter. From the analysis results of social media trends, we observed that the discussion about online learning was more popular than mobile learning on Twitter. While April was the month with the highest volume of tweets on online learning, February was the month with the highest volume of tweets on mobile learning. People talked about online/mobile learning more likely during the afternoon period than the other periods. Our related results can help educational practitioners to evaluate whether to add the hashtag of online learning in their tweets due to its popularity and choose the appropriate month, day, or time to post the tweets if they want to promote their online or mobile learning courses. Regarding the trends of online learning and mobile learning, we also observed that the posts about online learnings were retweeted more often than mobile learning, but the average number of online learning retweets was fewer than the one of mobile learning retweets. The results suggest that the Twitter users who concerned about mobile learning were more enthusiastic on reposting related information than the ones who concerned about online learning. We also identified the most retweeted tweets related to online learning and mobile learning as well as drew the volume trends of these tweets. Educational practitioners have to choose the timing of posting carefully for 
effective communication and interaction, because almost all of the retweets occurred within 1 hour after the original tweets were posted. Moreover, we also identified the top 10 hashtags related to online learning and mobile learning. Educational practitioners can refer this information to add the related popular hashtags in their postings for more readers. In addition, the analysis of influencers is another highlight of this study. We proposed three perspectives to identify the influencers of online learning and mobile learning on Twitter. The identification of social media influencers is important to educational practitioners, because these influencers play vital roles to disseminate information to their vast networks of followers and friends. Educational practitioners should build strong connections with the influencers and monitor their social media activities.

However, the presented research has some limitations. Our analysis is based on the 1-year data collected from Twitter. Further research might investigate other social media platforms such as Sina Weibo, one of the most popular microblogging sites in China. Different measures may be needed to identify the trends and influencers on other social media platforms. The social network diagram depicting how the tweets of online learning and mobile learning are disseminated form influencers can be further examined also to understand the relationships between top influencers. Moreover, though we propose several measures to identify the trends and influencers on Twitter, there are many other measures available. Further research can be conducted to evaluate the feasibility of other measures on the Twitter platform.

\section{Acknowledgements}

This research was supported by the Ministry of Science and Technology, Taiwan, R.O.C., under contract number MOST 104-2410-H-0o8-034.

\section{References}

Baird, D. E., \& Fisher, M. (2005). Neomillennial user experience design strategies: Utilizing social networking media to support "always on" learning styles. Journal of Educational Technology Systems, 34(1), 5-32.

Borondo, J., Morales, A., Losada, J. C., \& Benito, R. M. (2012). Characterizing and modeling an electoral campaign in the context of Twitter: 2011 Spanish Presidential election as a case study. Chaos: An Interdisciplinary Journal of Nonlinear Science, 22(2), 023138.

Brownson, S. (2014). Embedding social media tools in online learning courses. Journal of Research in Innovative Teach, 7(1), 112-118. 
Cochrane, T., Narayan, V., \& Oldfield, J.(2014). Emerging technologies in New Zealand: A pedagogical framework for mobile social media. In V. Bozalek, D. Ngambi, D. Wood, J. Herrington, J. Hardman, \& A. Amory (Eds.), Activity theory, authentic learning, and emerging technologies: Southern perspectives (pp. 126-143). New York: Routledge.

Dabbagh, N. (2004). Distance learning: Emerging pedagogical issues and learning designs. Quarterly Review of Distance Education, 5(1), 37.

Davis III, C. H. F., Deil-Amen, R., Rios-Aguilar, C., \& González Canché, M. S. (2015). Social Media, Higher Education, and Community Colleges: A Research Synthesis and Implications for the Study of Two-Year Institutions. Community College Journal of Research and Practice, 39(5), 409-422. doi:10.1080/10668926.2013.828665

Dunlap, J. C., \& Lowenthal, P. R. (2009). Tweeting the night away: Using Twitter to enhance social presence. Journal of Information Systems Education, 20(2), 129-135.

Fortin, D., Uncles, M., Burton, S., \& Soboleva, A. (2011). Interactive or reactive? Marketing with Twitter. Journal of Consumer Marketing, 28(7), 491-499.

Frohberg, D., Göth, C., \& Schwabe, G. (2009). Mobile learning projects-a critical analysis of the state of the art. Journal of Computer Assisted Learning, 25(4), 307-331.

Gikas, J., \& Grant, M. M. (2013). Mobile computing devices in higher education: Student perspectives on learning with cellphones, smartphones \&amp; social media. The Internet and Higher Education, 19, 18-26.

Greenhow, C. (2011). Youth, learning, and social media. Journal of Educational Computing Research, 45(2), 139-146.

Harasim, L. M. (1995). Learning networks: A field guide to teaching and learning online. Cambridge, MA: MIT Press.

Hong, L., Convertino, G., \& Chi, E. H. (2011). Language Matters In Twitter: A Large Scale Study. Proceedings of the Fifth International AAAI Conference on Weblogs and Social Media, 518-521. Barcelona, Spain: Association for the Advancement of Artificial Intelligence.

Khan, B. (2005). Learning features in an open, flexible and distributed environment. Association for the Advancement of Computing In Education Journal, 13(2), 137-153.

Lam, J., Yau, J., \& Cheung, S. K. (2010). A review of mobile learning in the mobile age. In P. Tsang, S.K.S. Cheung, V.S.K. Lee, and R. Huang (Eds.), Hybrid learning (pp. 306-315). Berlin Heidelberg: Springer, 
Lewis, S., Pea, R., \& Rosen, J. (2010). Beyond participation to co-creation of meaning: Mobile social media in generative learning communities. Social Science Information, 49(3), 351-369.

Liu, M.-C., \& Huang, Y.-M. (2015). Collaborative experience sharing with the support of M-Learning 2.0: a fundamental framework, a case study and research issues. International Journal of Mobile Learning and Organisation, 9(1), 21-37.

Lu, J., Yang, J., \& Yu, C.-S. (2013). Is social capital effective for online learning? Information \& Management, 5o(7), 507-522.

Naaman, M., Becker, H., \& Gravano, L. (2011). Hip and trendy: Characterizing emerging trends on Twitter. Journal of the American Society for Information Science and Technology, 62(5), 902918.

Norman, H., Nordin, N., Din, R., Ally, M., \& Dogan, H. (2015). Exploring the roles of social participation in mobile social media learning: A social network analysis. The International Review of Research in Open and Distributed Learning, 16(4).

Ostashewski, N., \& Reid, D. (2012). Delivering a MOOC using a social networking site: The SMOOC Design model. Proceedings of the IADIS International Conference on Internet Technologies \& Society, 217-220. Perth, Australia: International Association for Development of the Information Society.

Roblyer, M. D., McDaniel, M., Webb, M., Herman, J., \& Witty, J. V. (2010). Findings on Facebook in higher education: A comparison of college faculty and student uses and perceptions of social networking sites. The Internet and Higher Education, 13(3), 134-140.

Rothkrantz, L. (2014). New didactical models in open and online learning based on social media. Proceedings of the International Conference on e-Learning, 9-18. Lisbon, Portugal.

Sarsar, F., \& Harmon, S. (2011). Facebook as an online learning environment: Perceptions of undergraduate students. Proceedings in Society for Information Technology \& Teacher Education International Conference, 715-720 . Chesapcake, VA: Association for the Advancement of Computing in Education.

Shen, C.-w., \& Kuo, C.-J. (2015). Learning in massive open online courses: Evidence from social media mining. Computers in Human Behavior, 51, Part B, 568-577.

Shih, Y. E. (2007). Setting the new standard with mobile computing in online learning. The International Review of Research in Open and Distributed Learning, 8(2).

Shin, W.-Y., Singh, B. C., Cho, J., \& Everett, A. M. (2015). A new understanding of friendships in 
space: Complex networks meet Twitter. Journal of Information Science, 41(6), 751-764.

Sobaih, A. E. E., Moustafa, M. A., Ghandforoush, P., \& Khan, M. (2016). To use or not to use? Social media in higher education in developing countries. Computers in Human Behavior, 58, 296305.

Tess, P. A. (2013). The role of social media in higher education classes (real and virtual) - A literature review. Computers in Human Behavior, 29(5), A60-A68.

\section{Athabasca}

University

(c) (†) 